Original article

\title{
An exploratory spatial analysis of low birth weight and its determinants in India
}

\author{
Adrita Banerjee $^{\mathrm{a}}$, Ajeet Kumar Singh ${ }^{\mathrm{a}}$, Himanshu Chaurasia ${ }^{\mathrm{b}, *}$

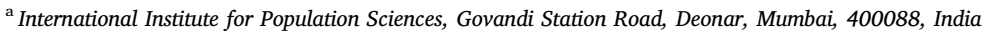 \\ ${ }^{\mathrm{b}}$ National Institute for Research in Reproductive Health (NIRRH), Indian Council of Medical Research (ICMR), Parel, Mumbai, India
}

\section{A R T I C L E I N F O}

\section{Keywords:}

Low birth-weight (LBW)

Ante-natal care (ANC)

Iron folic acid (IFA) tablets

Moran's I

LISA

\begin{abstract}
A B S T R A C T
Background: Low birth weight (LBW), defined as a live birth weighing less than $2500 \mathrm{~g}$, is a significant public health problem in India. The complex nature of this problem is not fully understood. Moreover, significant disparities in LBW prevalence not only documented across various socio economic groups but across states and districts as well. The identification of spatial patterns of LBW and its determinants is important for understanding epidemiology of this public health challenge.

Objective: This paper examines the determinants and spatial patterns of Low birth weight prevalence spatial pattern of LBW and its determinants in India.

Methods: Using fourth round of National Family Health Survey data, regression and spatial analysis have been performed through STATA, ArcGIS and GeoDa software.

Results: The result indicates lower odds of LBW prevalence among educated mothers, mothers who have more than 4 ANC visit, mothers who took IFA tablets during pregnancy, mothers with normal BMI and mothers with age above 20 years. The Moran's I for LBW is 0.543. It indicates high spatial autocorrelation in LBW over the districts of India The bivariate LISA maps obtained indicate spatial distribution of LBW and independent variables systematically contrasts the districts of central and eastern India (e.g. in Uttar Pradesh) with those of the extreme south (e.g. in Tamil Nadu, Kerala, etc.).

Conclusion: Our findings reveal greater attention towards maternal and child health care especially for the backward districts in the states of Uttar Pradesh (UP), Madhya Pradesh (MP), Bihar and Rajasthan are needed. Several maternal and social factors leads to the occurrence of low birth weight. Emphasis should be placed on improving the nutritional status of the mothers.
\end{abstract}

\section{Background}

Across the globe, low birth weight (LBW) prevalence is estimated to be around $15.5 \%$ making it a public health concern. ${ }^{1}$ A birth is considered as of low weight when the weight of the child at birth is less than $2500 \mathrm{~g}$ (WHO). The UNICEF estimates that almost 30 million children worldwide are born every year with a birth-weight of less than 2500 g. Born with a low weight may elevate subsequent adverse health consequence for the child. The immediate consequence of low birth weight is infant mortality, particularly in the first month of life. ${ }^{2-4}$ Children born with low weight tends to have retarded cognitive growth and IQ level. Children are the future of the society. Ill health at young age undermines their ability to work as adult. Immediate growth faltering and subsequent health adversities are not the only consequence of low birth weight. Low birth weight has long term risk in the form of high rates of adult coronary heart disease and type 2 diabetes. ${ }^{39}$

The weight of the child at birth depends on the health of the mother and behaviour during pregnancy. This in turn in affected by sociocultural as well as demographic characteristics. ${ }^{5,7,38}$ The maternal reproductive and behavioural factors like maternal race/ethnicity, age and education, parity, plurality, inadequate prenatal care, marital status, previous preterm birth, smoking, and pre-pregnancy body mass index has direct bearing on the weight of the child. ${ }^{8,9}$ Most of the low birth weight infants in developed countries are born prior to completion of gestation period i.e. the births are preterm births. But for the developing countries they are born at term and are mostly affected by intra uterine growth restriction that begins early in the pregnancy. ${ }^{10} \mathrm{In}$ a report published by World Health Organization in 1992, the existence of intergenerational growth failure was mentioned where the general pattern observed in many developing countries including India was that

\footnotetext{
${ }^{*}$ Corresponding author.

E-mail addresses: adrita.banerjee@yahoo.co.in (A. Banerjee), aksingh2789@gmail.com (A.K. Singh), himanshu.icmr369@gmail.com (H. Chaurasia).
} 
infant girls born with LBW continue to experience growth failure during early childhood and perhaps adolescence, most likely have children at an early age (which further reduces their opportunity to reach an optimal body size with adequate nutrient stores before conception), and thereby give birth to LBW infants. Economic, social and cultural factors further acts as compounds and make it difficult for the mother to obtain the required nutrition and health care. ${ }^{11,12}$

The data on low birth weight for developing countries are limited and thus a study of the trend in the same are also not found in much literature. The worldwide prevalence of low birth weight is really a matter of concern, but the major burden is felt on the developing countries. According to UNICEF report, in 2014 about $27 \%$ of the babies are born with low weight in South Asia. ${ }^{37}$ India is no exception to this. According to National Family Health Survey 2015 report 17\% of the babies are born with weight less than $2.5 \mathrm{~kg}$ in India. Low birth weight is a matter of public health concern. It not only reflects the health of the child, but points out the health status of the mother during her pregnancy period. Inefficient nutrient intake of the mother during her term would result in low weight of the child. Yet, this health concern has not much been addressed in Indian context. A lot of literature points out the importance of location, spatial interaction and spatial process in public health issues. ${ }^{14,15}$ Location plays an important role in determining the depth of the health issue. A number of studies have been found in the developed countries of North America that examines the spatial patterns of LBW prevalence, as well as the presence of spatial clusters both at country level and census tracks. ${ }^{16,17}$ In a study conducted by ${ }^{18}$ in Kaniyambadi block in southern state of Kerala $16.8 \%$ of the births were of low weight. The five-yearly trend for LBW at the villagelevel revealed a slight decline in the magnitude of LBW from 1991 to 1995 to $2006-2010$ by $2.95 \%$. A significant spatial clustering was also observed in the blocks. A study of spatial pattern and clustering of public health issues helps in identifying the zones (clusters) which have greater problems and needs much focus.

Although studies have been conducted in India which deals with the prevalence and determinants of low birth weight, ${ }^{18,19}$ but none have talked about the variation in LBW prevalence at the state and district level. Studies in India are mostly hospital based studies conducted in specific parts of the country. ${ }^{20}$ There is a widespread disparity in the prevalence of LBW across various socioeconomic classes. Significant variation exists among the states as well as the districts within the states. With under reporting of birth weight data limited work has been done in this field.

In the case of individual-based analyses, much of the spatial variation may not be easily observable among children of low birth weight. Health data is often useful if geo-referenced, i.e. linked to geographic locations. Geographic Information Systems (GIS) technology provide a platform for both the powerful visualization of data and analysis which is spatially-driven. Thus, spatial analysis technique is useful in defining exposure-outcome relationships for better understanding of health aspects that exhibit spatial phenomena, hence spatial effects are important, as they may invalidate certain standard methodological results and may be used to develop better research hypotheses. Ignoring spatial effects gives rise to artificially low standard errors ${ }^{21}$; and. ${ }^{22}$ No studies to date have analysed the spatial patterns of LBW prevalence and its major determinants in India. Thus, this paper takes the approach of analysing the spatial pattern of low birth weight prevalence across the districts the study also tries to explore the factors that determine the prevalence at individual level. It also aims to test spatial correlations between variables, i.e. whether an inter-relation can be found between the spatial distribution of LBW prevalence and a range of other variables.

\section{Methods}

\subsection{Data source}

We have used National Family Health Survey Round 4 data collected during 2015-16 by the International Institute for Population Sciences (IIPS), Mumbai, under the stewardship of the Ministry of Health and Family Welfare (MoHFW), Government of India. The primary objective of the survey is to provide essential data on health and family welfare, as well as data on emerging issues in these areas. The NFHS-4 was a nationwide representative sample survey of 601,509 households, 699,686 women in the age group 15-49 years. The survey provides district wise information on fertility, infant and child mortality, the practice of family planning, maternal and child health, reproductive health, nutrition, anaemia, utilization and quality of health and family planning services fertility, mortality, morbidity, and maternal and child health for all 29 states and 7 UTs covering more than $99 \%$ of national population.

\subsection{Sampling plan survey design}

Multistage stratified sampling methods were used to create a sample representing individuals from all 29 Indian states. The sample size of each state was proportional to the population and the sample was stratified by urban and rural residence within states. Within state strata, primary sampling units (PSUs) were selected based on probability proportional to population and were villages or clusters of villages in rural areas, and census enumeration blocks within urban areas. Households were randomly selected within PSUs. Within selected households, all women aged 15-49 years were eligible to be respondents in the survey.

\subsubsection{Outcome Variable}

The outcome variable used in the analysis is the birth weight (measured in grams). Low birth weight is not only a significant predictor of infant health issues like infant mortality but also points out the maternal health condition. ${ }^{6}$ NFHS had collected information on the birth weight of the last child and the information is based on both mother's recall and from the written card. After correcting for all the missing values, there are 31,928 low birth-weight babies and 155,254 normal weight babies born. The birth weight has been categorised into two groups, low birth weight (less than $2500 \mathrm{~g}$ ) as defined by the World Health Organization (WHO) and normal i.e. weight equal to or more than $2500 \mathrm{~g}$.

\subsection{Socioeconomic variables}

Extensive review of literature has helped in identifying a host of predictor variables for the analysis. ${ }^{23-25}$ Accordingly a number of socioeconomic variables have been used. These include religion, caste, wealth index, place of residence, mother's education, employment status. Apart from these a number of demographic variables pertaining to maternal health condition has also been used. These include birth order $(1,2-3,4-5,6+)$, ante-natal care visit (no visit, up to 4 visit and more than 4 visit), Iron Folic Acid (IFA) tablet intake during pregnancy (yes, no), tetanus injection taken during pregnancy (yes, no), mother's nutritional status (underweight, normal and overweight), mother's age (less than 20 years, 20-34 years and 35-49 years) and mother is suffering from anaemia or not (anaemia categorised into not anaemic, mild or moderately anaemic and severely anaemic).

\subsection{Statistical analysis}

We chose individual and district as the unit of analysis for bivariate and spatial analysis respectively. The analysis has been done in two parts. Firstly, bivariate analyses have been carried out to assess the 
prevalence of low birth weight based on the socio-economic and demographic characteristics. After checking for multi-collinearity, binary logistic regression has been done to test the effect of confounding factors associated with the occurrence of low birth weight. Multi-collinearity occurs when independent variables in a regression model are correlated. If the degree of correlation between variables is high enough, it can cause problems when one tries to fit the model and interpret the results. In the analysis, the variance inflation factor (VIF) has been used to check for multi-collinearity. Here first a normal linear regression is first run and then after obtaining the normal $\mathrm{R}^{2}$ value the VIF is calculated as:

$\mathrm{VIF}=1 /\left(1-\mathrm{R}^{2}\right)$

The statistical significance of variation in the prevalence of low birth weight estimated as an adjusted odds ratio with $95 \%$ confidence interval across the categories of the predictor variables has been checked. The entire analysis has been carried out using STATA 13.

The second part of the study caters to spatial analysis. For that, descriptive maps had been generated using ArcGIS which were exported to GeoDa for spatial analysis, First-order contiguity matrix has been used as weight for analysis purpose. The dependent variable for the analysis is the district wise percentage of low-birth weight children. The independent variables include district wise percentage of first order birth, percentage of educated mothers, percentage of women with no ANC visit, percentage of women taking IFA tablets and TT injections during pregnancy, percentage of anaemic women, percentage of women belonging to poorest wealth quintile, percentage of women living in urban area, percentage of currently mother's less than 20 years age and percentage of underweight mother's. The percentage distributions of the aforesaid independent variables have been calculated for all the 640 districts.

Moran's I, univariate and bivariate Local Indicators of Spatial Association (LISA) has been estimated. Moran's I is the Pearson coefficient measure of spatial autocorrelation ${ }^{41}$ which measures the degree to which data points are similar or dissimilar to their spatial neighbours. Negative values indicate negative spatial autocorrelation and a positive value indicates a positive spatial autocorrelation. Positive autocorrelation indicates that points with similar characteristics are closely distributed in space, whereas negative spatial autocorrelation indicates that closely associated points are more dissimilar. Values of I range from -1 (indicating perfect dispersion) to +1 (perfect correlation). A zero value indicates a random spatial pattern. Univariate LISA measures the correlation of neighbourhood values around a specific spatial location. It determines the extent of spatial clustering present in the data. Bivariate LISA measures the local correlation between a variable and the weighted average of another variable in the neighbourhood.

Spatial error model available in GeoDa has also been done to examine the relationship between dependent and the independent variables. ${ }^{31}$ This model evaluates clustering of an outcome variable that is not explained by the independent variables. Spatial clustering is explained with reference to the clustering of the error terms. The spatial error model can be mathematically expressed as

$y=X b+u$

with,

$u=m \cdot$ W.u. + e

where, $\mathrm{u}$ is the model prediction error; e are the residues (spatially uncorrelated); $\mathrm{m}$ is the spatial auto regressive parameter; and $\mathrm{W}$ is the spatial weights matrix.
Table 1

Percentage distribution of Low Birth Weight (LBW) based on maternal factors and Socio-economic factors in India, 2015-16.

\begin{tabular}{|c|c|c|c|}
\hline Maternal factors & & Socio-economic factors & \\
\hline Background Variables & Percentage & Background Variables & Percentage \\
\hline Birth Order & & Education Level & \\
\hline 1 & 18.56 & No education & 19.43 \\
\hline $2-3$ & 16.72 & Primary & 19.55 \\
\hline $4-5$ & 18.2 & Secondary & 17.37 \\
\hline $6+$ & 17.88 & Higher & 13.77 \\
\hline IFA Tablet Taken & & Employment status & \\
\hline Yes & 16.63 & Employed & 16.95 \\
\hline No & 19.59 & Unemployed & 17.21 \\
\hline TT Injection & & Place of Residence & \\
\hline Yes & 17.51 & Urban & 17.17 \\
\hline No & 20.47 & Rural & 17.88 \\
\hline ANC Visit & & Religion & \\
\hline No visit & 19.98 & Hindu & 17.9 \\
\hline Up to 4 visits & 17.63 & Muslim & 16.8 \\
\hline More than 4 visits & 16.01 & Christian & 16.88 \\
\hline Anaemia & & Others & 15.85 \\
\hline Severe & 23.17 & Caste & \\
\hline Mild/moderate & 17.94 & General & 16.49 \\
\hline Not anaemic & 17.16 & OBC & 17.17 \\
\hline Age of Mother & & SC & 18.47 \\
\hline$<20$ & 20.47 & ST & 19.83 \\
\hline $20-34$ & 17.58 & Wealth Index & \\
\hline $35-49$ & 17.37 & Poorest & 19.1 \\
\hline BMI & & Poorer & 17.78 \\
\hline Underweight & 21.03 & Middle & 17.1 \\
\hline Normal & 17.05 & Richer & 16.76 \\
\hline Overweight & 15.01 & Richest & 14.64 \\
\hline Total & 31,928 & Total & 31,928 \\
\hline
\end{tabular}

\section{Results}

\subsection{Prevalence of low birth weight and its predictors}

Table 1 presents the percentage distribution of birth weight of the last child based on certain maternal characteristics. Out of the total sample of last birth and checking for all the missing values, 31,928 are low birth weight babies. It is seen from the table that the 1st order children have more chances of having low weight at birth compared to the subsequent birth order children. Not much variation is found in the birth outcome of women who took IFA tablet and tetanus injection during pregnancy compared to those who did not take the same. The antenatal care visit has been categorised into 3 categories, those pregnant women who did not go for any visit, those who went for up to 4 visits and those who went for more than 4 visit. Women who went for more than 4 ANC visit had lesser chance of having low weight babies. Women who have severe anaemia, the probability of low birth weight babies among them is higher compared to those women who have mild/moderate anaemia and those who are nonanaemic. Age of the mother is also an important determinant of LBW as young mothers with age less than 20 years have more LBW babies. Nutritional status is also an important cause of LBW as underweight women have greater number of LBW babies. Educated mothers had lesser number of LBW babies compared to women who did not receive any education. LBW prevalence is also higher among unemployed mothers. Not much difference is observed in the percentage of LBW babies among rural and urban areas but the inclination is more towards the rural areas. . Low birth weight prevalence is higher among Hindus compared to other religious groups. Low birth weight is found to be more among ST and SC population compared to general and OBC groups. Low birth weight prevalence is higher among poorest quintile and lowest among the richest quintile. 
Table 2

Adjusted odds ratio (aO.R) Of prevalence of low birth weight (LBW) in India, 2015-16.

\begin{tabular}{|c|c|c|c|c|c|c|c|}
\hline Background & aO.R & 95\% C.I & & Background & aO.R & $95 \% \mathrm{C}$. & \\
\hline Variables & & LL & UL & Variables & & LL & UL \\
\hline Educational Status & & & & Religion & & & \\
\hline No Education & & & & Muslim & & & \\
\hline Primary & 1.02 & 0.904 & 1.157 & Hindu & 0.97 & 0.866 & 1.092 \\
\hline Secondary & $0.89 * *$ & 0.803 & 0.989 & Christian & $0.57 * * *$ & 0.472 & 0.691 \\
\hline Higher & $0.75^{* * *}$ & 0.647 & 0.882 & Others & $0.81 * *$ & 0.668 & 0.972 \\
\hline Place of Residence & & & & TT Injection & & & \\
\hline Urban & & & & No & & & \\
\hline Rural & $0.89 * * *$ & 0.822 & 0.982 & Yes & 0.91 & 0.781 & 1.063 \\
\hline Employment Status & & & & IFA Tablet & & & \\
\hline Unemployed & 0.95 & 0.871 & 1.038 & No & & & \\
\hline Employed & & & & Yes & $0.92^{*}$ & 0.836 & 1.016 \\
\hline ANC & & & & BMI & & & \\
\hline No visits & & & & Underweight & & & \\
\hline Up to 4 visits & $0.87^{* *}$ & 0.776 & 0.985 & Normal & $0.77 * * *$ & 0.716 & 0.847 \\
\hline More than 4 visit & $0.88^{* *}$ & 0.777 & 0.999 & Obesity & $0.70 * * *$ & 0.621 & 0.791 \\
\hline Caste & & & & Birth Order & & & \\
\hline General & & & & 1 & & & \\
\hline OBC & 1.03 & 0.934 & 1.135 & $2-3$ & $0.86^{* * *}$ & 0.798 & 0.936 \\
\hline SC & 1.09 & 0.973 & 1.229 & $4-5$ & 0.94 & 0.821 & 1.077 \\
\hline ST & 0.96 & 0.844 & 1.095 & $6+$ & 0.97 & 0.763 & 1.235 \\
\hline $\begin{array}{l}\text { Mother's Age } \\
<20\end{array}$ & & & & $\begin{array}{l}\text { Wealth Quin } \\
\text { Poorest }\end{array}$ & & & \\
\hline $20-34$ & $0.81^{* *}$ & 0.673 & 0.984 & Poorer & 0.97 & 0.864 & 1.085 \\
\hline $35-49$ & $0.80^{*}$ & 0.636 & 1.013 & Middle & 1.00 & 0.886 & 1.129 \\
\hline Anaemia & & & & Richer & 1.01 & 0.879 & 1.149 \\
\hline Severe & & & & Richest & $0.87^{*}$ & 0.749 & 1.02 \\
\hline Moderate/mild & 0.85 & 0.624 & 1.162 & & & & \\
\hline Not anaemic & 0.83 & 0.61 & 1.14 & & & & \\
\hline
\end{tabular}

Note: $* *$ indicates $\mathrm{p}<0.01, * *$ indicates $\mathrm{p}<0.05$, * indicates $\mathrm{p}<0.10$.

C.I: Confidence Interval, a.O.R: adjusted odds ratio.

\subsection{Adjusted odds ratio of prevalence of low birth weight ( $L B W$ ) and its determinants}

Table 2 presents the logistic regression results for prevalence of low birth weight (LBW) after controlling for all the background characteristics. The adjusted odds of low birth weight prevalence were found to be low among women who had secondary (aOR $=0.89, \mathrm{p}<0.05)$ and higher $(\mathrm{aOR}=0.75, \mathrm{p}<0.05)$ educational level compared to women without any education. While moving from higher to lower birth order the adjusted odds of the prevalence of low birth weight. It has been found to be low. 2-3 birth order had lower odds of prevalence of low birth weight $(\mathrm{aO} . \mathrm{R}=0.86, \mathrm{p}<0.01$ ) compared to 1 st order births. The odds of low birth weight was lower for women who had up to 4 ANC visit (aO.R $=0.87, \mathrm{p}<0.05$ ) and more than 4 visits (aO.R $=0.88, \mathrm{p}<0.05$ ) compared to women who never went for ANC visit. Normal $(\mathrm{aO} . \mathrm{R}=0.77, \mathrm{p}<0.01)$ and obese $(\mathrm{aO} . \mathrm{R}=0.70$, $\mathrm{p}<0.01$ ) women have lower odds of prevalence of low birth weight compared to underweight women. Women who took IFA tablets at the time of pregnancy has lower odds of low birth weight $(\mathrm{aO} . \mathrm{R}=0.92$, $\mathrm{p}<0.10$ ) compared to women who did not take any IFA tablets. The adjusted odds of LBW has been found to be lower among mothers whose age is 20-34 (aO.R $=0.81, \mathrm{p}<0.05)$ and 35-49 (aO.R $=0.80$, $\mathrm{p}<0.10$ ) years compared to mothers with age less than 20 years. The odds of LBW is low among the Christian ( $\mathrm{aO} . \mathrm{R}=0.57, \mathrm{p}<0.01)$ and other $(\mathrm{aO} . \mathrm{R}=0.81, \mathrm{p}<0.01)$ compare to the Hindus. The odds of prevalence of LBW is lower in the rural area (aO.R $=0.89, \mathrm{p}<0.05)$ compared to urban areas. The adjusted odds of prevalence of LBW is lower among the richest wealth quintile $(\mathrm{aO} . \mathrm{R}=0.87, \mathrm{p}<0.10)$ compared to the poorest quintile.

\subsection{Spatial autocorrelation}

Table 3 presents the Moran's I values for the dependent and
Table 3

Moran's I for the dependent and independent variables.

\begin{tabular}{lc}
\hline Selected Variables & Moran's I \\
\hline LBW & 0.543766 \\
Birth order & 0.546965 \\
Educated & 0.676809 \\
No ANC visit & 0.595904 \\
Anaemic & 0.521778 \\
Urban & 0.416565 \\
Age less than 20 years & 0.517197 \\
Poorest & 0.758664 \\
Underweight & 0.675294 \\
IFA & 0.674371 \\
TT Injection & 0.546123 \\
\hline
\end{tabular}

independent variables included in the analysis. The Moran's I for LBW is 0.543. It indicates high spatial autocorrelation in LBW over the districts of India. Spatial autocorrelation is positive when similar values occur near one another in space. Results indicate that the districts with similar LBW are near one another. Moran's I is highest for the poorest wealth quintile (0.758) and lowest for the urban (0.41). Most of the independent variables have a Moran's I value more than 0.5 . These include 1st birth order (0.54), \% of educated women (0.67), women not going for any antenatal visit during pregnancy (0.59), anaemic women (0.52), mothers with age less than 20 years (0.52), underweight women (0.68), women taking IFA tablets during pregnancy (0.67), and women taking TT injections during pregnancy (0.54). The high Moran's I statistics clearly indicate substantial spatial autocorrelation in the variables included in the analysis.

\subsection{Spatial error model}

In order to see whether a value observed in one location depends on 
Table 4

Results of spatial error regression model.

\begin{tabular}{lll}
\hline Selected Variables & Spatial Error Regression (SER) & Probability \\
\hline Birth order & 0.125781 & 0.00096 \\
Educated & -0.015384 & 0.47698 \\
No ANC visit & 0.111351 & 0 \\
Anaemic & 0.027034 & 0.13577 \\
Urban & -0.007724 & 0.48954 \\
Age less than 20 years & -0.011964 & 0.90832 \\
Poorest & -0.039704 & 0.07256 \\
Underweight & 0.173952 & 0 \\
IFA Tablet & -0.059085 & 0.01759 \\
TT Injection & 0.093691 & 0.04262 \\
\hline Spatial Autocorrelation & 0.674075 & \\
R2/Pseudo R2 & 0.528961 & \\
No of Observation & 640 & \\
\hline
\end{tabular}

the values observed at neighbouring locations i.e. spatial dependence, spatial error model has been used which is presented in Table 4. The models show spatial clustering while examining association between LBW and independent variables. It is seen from the model that first order birth has a positive relation with low birth weight. Women not receiving or going for ANC also has a positive relation with low birth weight. Underweight mother has a positive relation with low birth weight, while intake of IFA tablet has a negative relation. The spatial autocorrelation is indicated by the lambda value of 0.674 which indicates that there is spatial dependence.

\subsection{LISA maps}

Fig. 1 shows the distribution of low birth weight prevalence across the districts of India. Higher percentage of low birth weight children are found in few districts of Rajasthan, Gujarat and UP while lesser percentage of LBW children are found in the districts of North eastern India as well as in Jammu and Kashmir.

Fig. 2 shows the LISA map for the low birth weight prevalence. The cluster map shows locations that have significant local Moran's I values classified by the type of spatial correlation. The dark red colour indicates highhigh association, the dark blue indicates low-low association, the light red colour indicates a high-low association and the light blue indicates a low-high association. For example, high-high LBW means that districts with aboveaverage prevalence of LBW also share boundaries with neighbouring districts that have above-average prevalence of LBW (Fig. 2). On the other hand, high-low means that districts with above-average LBW's are surrounded by districts with below average values. High-high are also referred to as hot spots and low-low as cold spots. ${ }^{40}$ It is seen from Fig. 2 that high-high clusters of low birth weight are found mostly in districts of northern, central and western states of India, while the low-low clusters are mostly found in the northeastern states.

Fig. 3 presents bivariate maps depicting the association between LBW and selected independent variables. The independent variables include percentage of educated females, percentage of 1st order births, percentage of women with no ANC visit during pregnancy, percentage of women with non-intake of Tetanus Injections and IFA tablets during pregnancy, percentage of underweight women, percentage of mothers with age less than 20 years, and percentage of women belonging to poorest wealth quintile and living in urban areas. Fig. 3A shows the high-high association between birth order and LBW in 26 districts scattered in parts of northern and western parts of the country. Lower percentage of 1st birth order is associated with higher percentage of LBW for 73 districts of UP, MP. Higher percentage of 1st order birth is associate with lower percentage of LBW in 39 districts particularly in North Eastern states. Fig. 3B shows that lower percentage of educated mother is associated with higher percentage of LBW children in 62 districts mostly in Uttar Pradesh, Madhya Pradesh and Gujarat. The higher percentage of educated mother is associated with low percentage of LBW for 65 districts mostly in the North eastern states ... Fig. 3C shows that high-high association between no ANC and LBW is observed in about 45 districts in UP, MP and Maharashtra. Similarly, 55 districts mostly in North Eastern India and some southern states have a lower percentage of no ANC visits and lower percentage of LBW. Low-high association between no ANC visit and low birth weight is observed in about 51 districts mostly in UP and Gujarat. Fig. 3D shows the association of LBW with age of mother less than 20 years. Higher percentage of mothers less than 20 years and higher percentage of LBW children are found in about 28 districts scattered in UP, Rajasthan, Maharashtra and MP. Lower percentage of mothers with age less than 20 years is associated with higher percentage of LBW in 60 districts scattered throughout the country mostly in NE and southern states. Higher percentage of mothers with age less than 20 years are associated with lower percentage of LBW children in about 32 districts mostly in North Eastern India. Fig. 3E shows association between percentage of anaemic mother and percentage of LBW children Higher the percentage of anemic mother higher is the percentage of LBW children in 57 districts of UP, Rajasthan, Gujarat, and Maharashtra. Low percentage of anaemic mother and lower percentage of LBW children are seen in 63 districts in North eastern India. Fig. 3F shows the association between underweight mother and low birth weight children. High-high association is found in 53 districts in UP, Gujarat, Rajasthan, MP and Maharashtra. Low-low association between the two is observed in 62 districts in NE states and scattered in 2 districts of Gujarat and 2 districts of southern states of Kerala and Tamil Nadu. . Fig. 3G shows that about 37 districts in Gujarat and UP with high percentage of poorest population has high LBW children. About 63 districts have lower percentage of poorest population and hence low birth weight. These are the districts in NE India, Gujarat and Jammu \& Kashmir. 52 districts in Uttarakhand, UP, Rajasthan, Gujarat have a lower percentage of poorest population but have higher percentage of LBW children. Fig. $3 \mathrm{H}$ shows the association of LBW and urban population. High percentage of urban population and higher percentage of LBW is seen in about 44 districts scattered mostly in northern, central and western states. Lower percentage of urban population and higher percentage of LBW is found in about 52 districts in UP, Gujarat, Rajasthan. Fig. 3I shows the association of non-intake of IFA tablet during pregnancy and LBW. Highhigh association between non-intake of IFA and LBW is found in 59 districts of Northern and western states Fig. 3J shows the association between intake of TT injections during pregnancy and LBW. Lower percentage of TT injection intake is associated with higher percentage of LBW in areas again in UP, Gujarat, Rajasthan. Higher percentage of TT injection intake is associated with lower percentage of LBW mainly in NE districts.

\section{Discussion}

The major determinants of low birth weight have come out to be ANC visit during pregnancy, mother's education, mother's age at marriage and nutritional status of the mother. Among the socio-economic variables wealth quintile and religion has also come out to be distinguished determinants of low birth weight. The primary objective of this paper is to study the spatial pattern of LBW prevalence and its determinants. Study of spatial clustering pattern in public health issues is of utmost importance as it helps in immediate intervention at the lowest level. The spatial error model presented shows the dependency of the LBW prevalence on its determinants based on the neighbouring effect. For the spatial analysis also women not receiving or going for ANC also has a positive relation with low birth weight. Underweight mother have a positive relation with low birth weight, while intake of IFA tablet has a negative relation. Similar association has been noticed in the LISA maps as well.

In India there is a tradition of early marriage which results in 


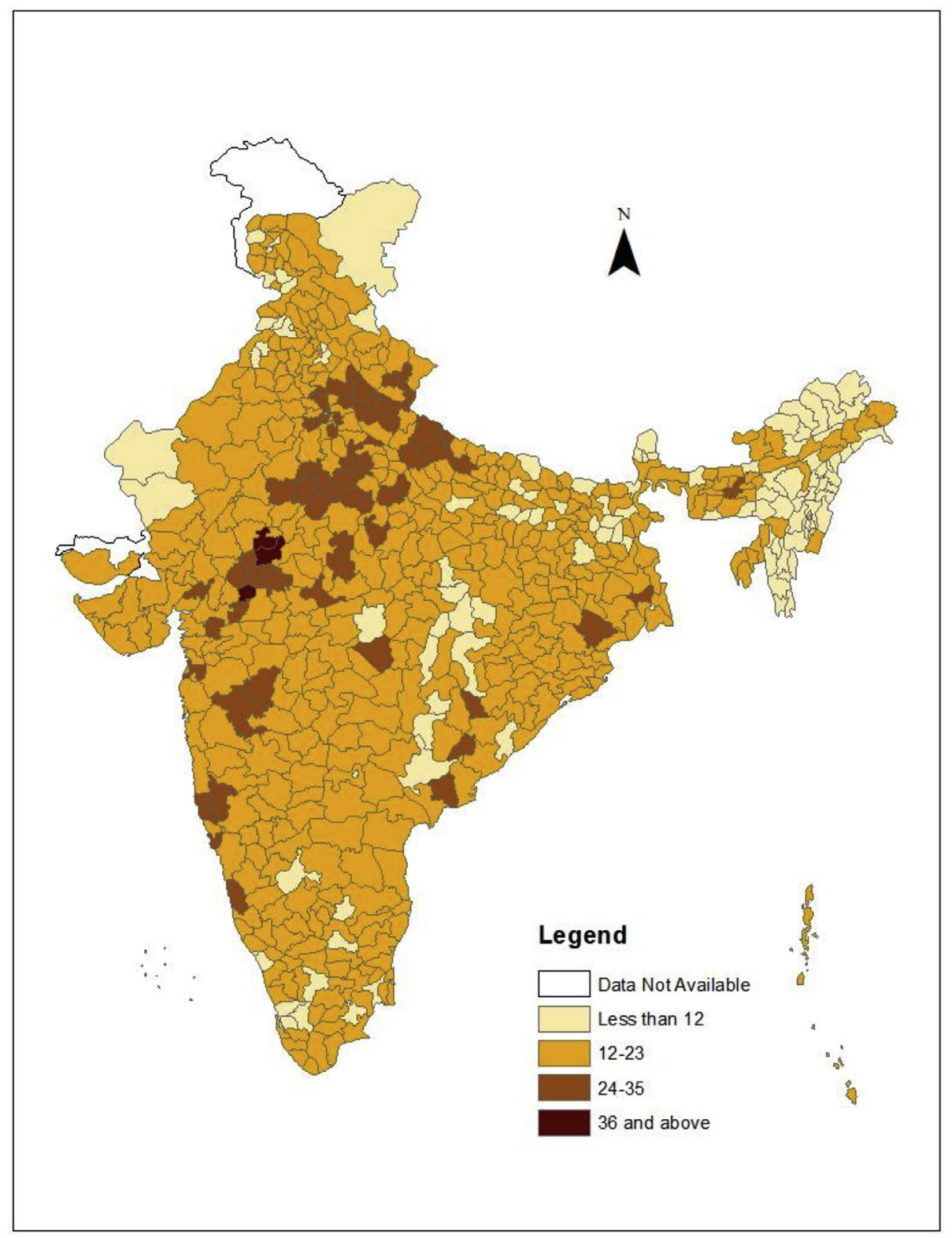

Fig. 1. Distribution of Low Birth Weight across districts.

teenage pregnancy. Deficit nutrition causes undernutrition among the pregnant women, which leads to limited intra-uterine growth ultimately causing low birth weight. ${ }^{26}$ With the ante natal care scheme initiated by the Government of India under various programmes related to maternal health, the prevalence of LBW has reduced as it is seen that women who went for more than 4 ANC visit has lesser chance of having low birth weight babies. The ANC visit for the women implies that they are being provided with necessary care during pregnancy, thus reducing chances of adverse pregnancy outcomes. Low birth weight showed significant association with parity and order. ${ }^{27}$ The first born child always has low birth weight. The mother's at the time of the first birth are mostly of lower ages and knows very little about their health needs which results in greater prevalence of low birth weight babies among them. Studies also reveals that education has a significant impact on health enhancing behaviour and less educated mothers have greater chances of having a low birth weight child.

As has already been mentioned with intervention programmes like NRHM and ICDS schemes, maternal health has been an important focus area. With the primary mission to improve the health of women and children, the government of India has set up the ministry of Women and
Child development which has expanded over time to cover pregnant and adolescent and teenage girls. Various maternal health related schemes under National Health Mission (NHM-Rural and urban) have also contributed in reaching an optimum health condition of the mother during pregnancy and thus improved birth weight of new born babies. Though there has been a reduction in low birth weight prevalence over time, yet the present figures are quiet disturbing, which makes it a public health concern. Necessary nutrients in right amount for the mothers is the foremost need to reduce the prevalence of low birth weight. With socio-economic inequality that exists in the Indian context, many women lack the essential food requirements during pregnancy. Though efforts have been made by the government to bridge this gap, but widespread disparity exists in terms of provision of various facilities initiated by the government. Increase in demand of both ante natal and post-natal services puts a pressure on the supply side, thus making the provisions inaccessible to many pregnant women. Nevertheless, the focus must be on what should be done. Improving dietary intakes during pregnancy is an obvious solution. Provision of food supplementation is not the only task. There is a need of behavioural change among the mother and her family members and thus a 


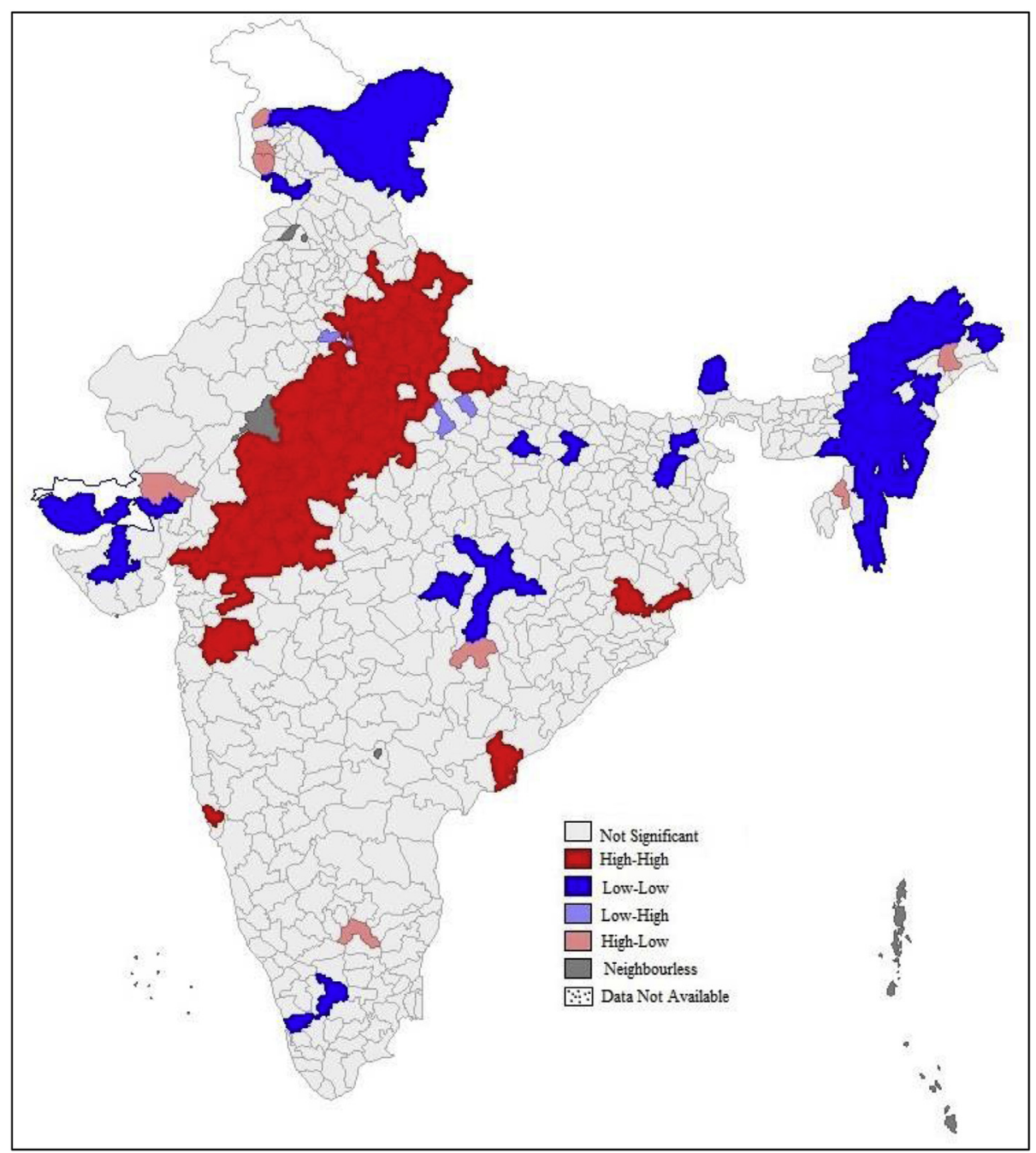

Fig. 2. Univariate LISA maps showing the clustering of Low Birth Weight.

need of creating awareness regarding dietary practices among mothers during pregnancy. A study made by Kramer and Kakuma in 2003 concludes that balanced protein-energy supplements during pregnancy can reduce the incidence of small-for-gestational-age infants by almost one-third. ${ }^{36}$ In particular, the study by Ceesay et al in Gambia showed significant reductions in both LBW and neonatal mortality, especial during periods of low food intake and high energy expenditure. ${ }^{32}$ Women should focus more on their nutrient intake during their pregnancy. With proper post-natal care for these low birth weight babies, they might overcome the risk of further complex health adversities. Governmental policies should focus on providing efficient nutrition to women who are expecting the first child. The ANC check-up should focus more on weight of the pregnant women and should keep a check on it so as to ascertain the weight of the child at birth. This would lessen the probabilities of further complications. Improving the prevalence of low birth weight would be given the utmost priority in the child health policies.

The study indicates marked variability of LBW prevalence at the district level. In addition, the significant positive spatial autocorrelation identified by Moran's I statistic as well as significant local clusters identified by LISA, confirm the presence of spatial heterogeneity in LBW rates. ${ }^{28}$ A similar pattern of spatial auto correlation have been identified in studies carried out in the United States. ${ }^{29,30}$ Thus an illustrative study on spatial clustering of determinants of low birth weight is essential from the policy perspective. This information would be quiet useful to health planners because many current policies or health initiatives are principally based on the assumptions of spatial homogeneity.

Districts are the lowest administrative units and the levels at which policies and programmes are implemented. But due to data constraints there are no studies in India till date that have analysed the LBW prevalence and its determinants at the district and nor a spatial autocorrelation of the available data. This paper has tried to explore the prevalence of low birth weight with the available data that covers about $80 \%$ of the births. A work in this field effectively would point put towards the needs of the policies in this areas. Policy intervention is not the only requirement. A continuous assessment of the given policies is a necessary step.

\section{Limitations of the study}

This study uses large scale data, which provides information based on mother's recall. This sometimes creates a bias in reporting the exact weight of the child at birth. The study also does not include dietary intake of the pregnant women, so the list of factors associated with prevalence of low birth weight could not be ascertained.

\section{Author contributions}

Conceived and designed the research paper: AKS; analysed the data: $\mathrm{AB}, \mathrm{AKS}$, and $\mathrm{HC}$; Contributed agents/materials/analysis tools: $\mathrm{AB}$, and AKS; Wrote the manuscript: AB, HC, and AKS; Refined the manuscript: 


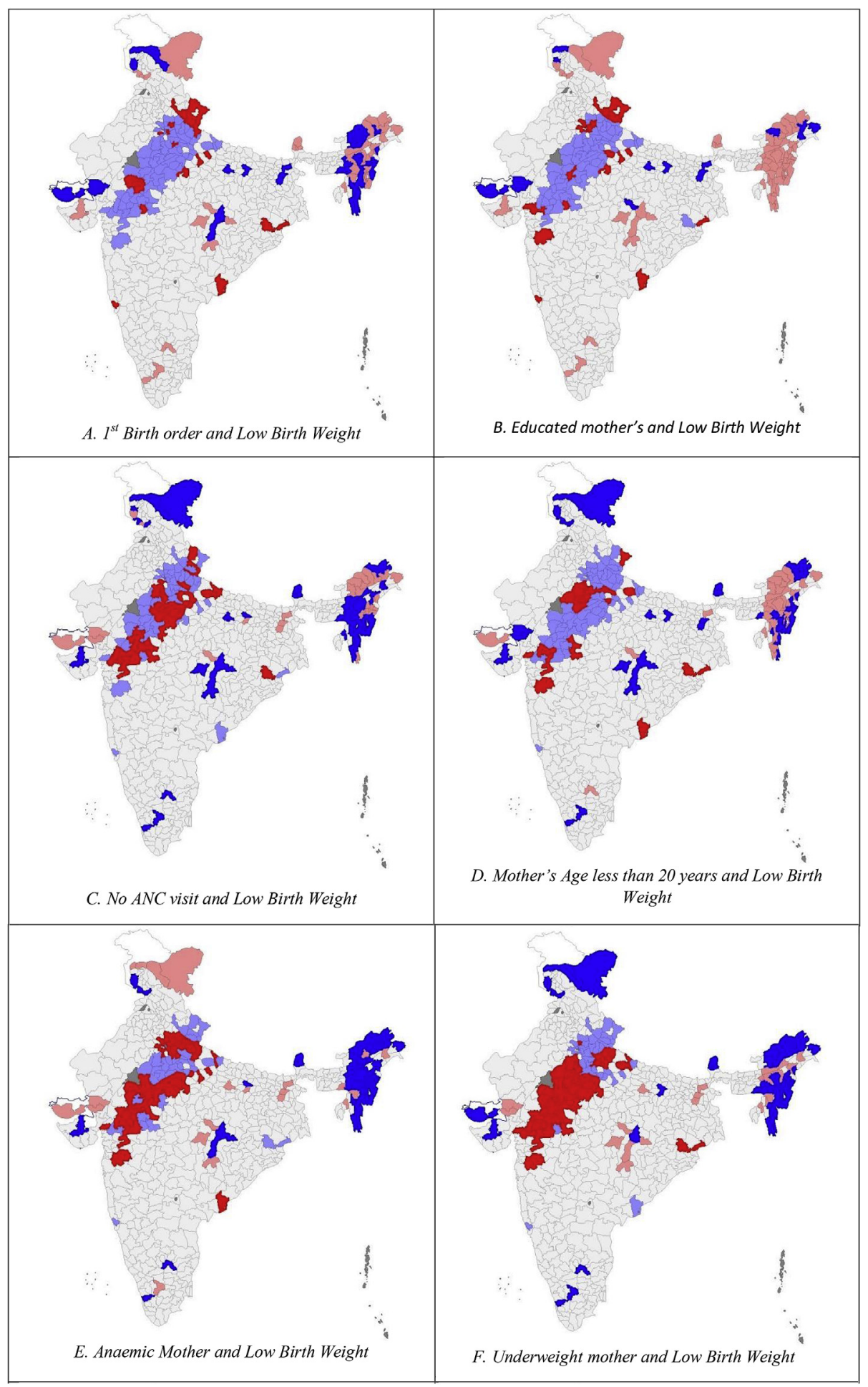

Fig. 3. Bivariate LISA maps showing spatial correlation between dependent and independent variable.

$\mathrm{HC}, \mathrm{AB}$, and AKS.

\section{Informed consent}

Informed consent was obtained from all individual participants included in the study.

\section{Ethical treatment of experimental subjects (animal and human)}

Disclosure of potential conflicts of interest has been provided. This study was based on a large dataset that is publicly available on DHS website (https://dhsprogram.com/data/) conducted by the MOHFW and International Institute for Population Sciences (IIPS) in India with ethical standards being complied with including informed consent obtained from participants.

\section{India digital map}

The district level shape file of India was acquired from GitHub at https://github.com/datameet/maps/tree/master/Districts. The digital 


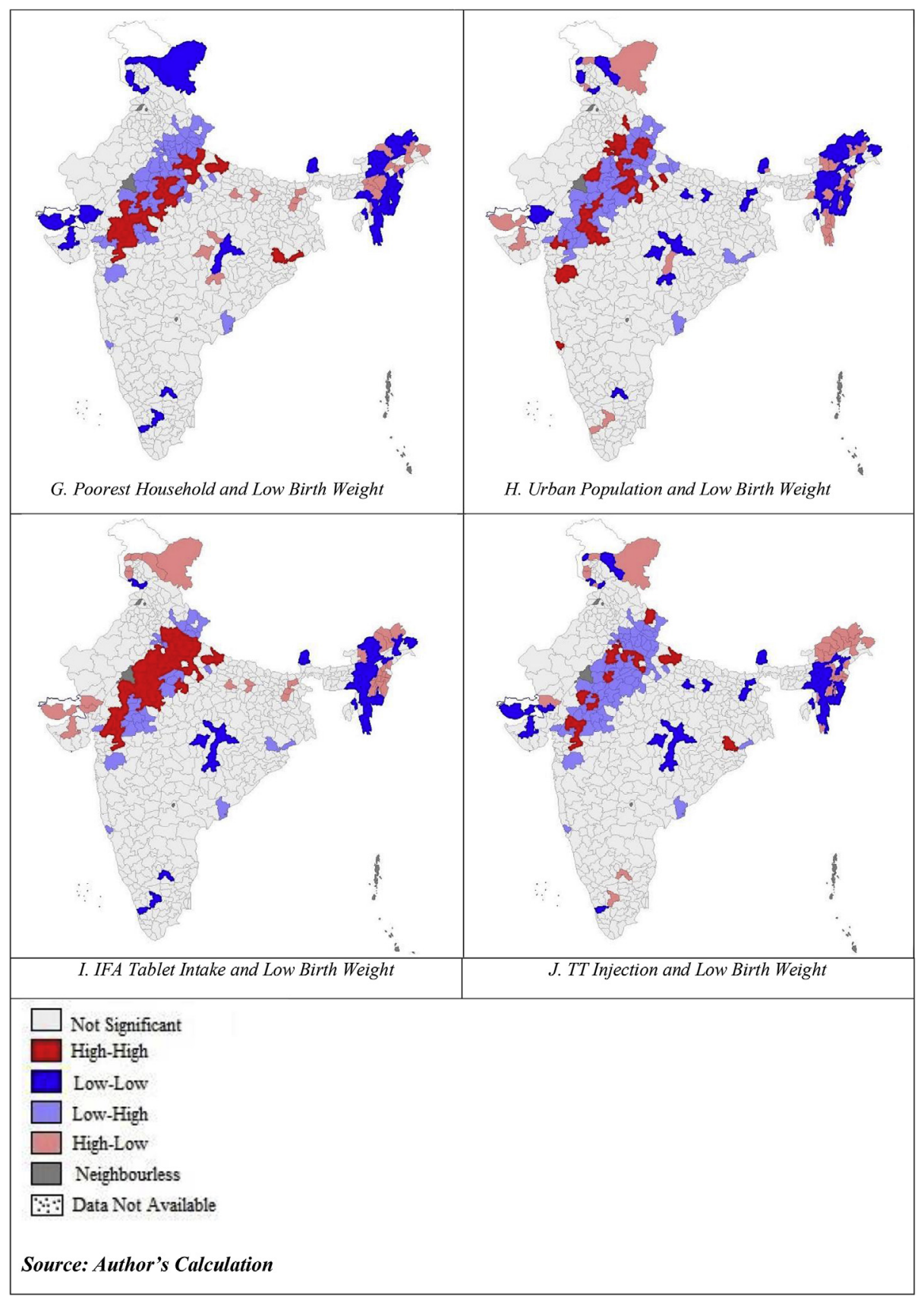

Fig. 3. (continued)

map has been used under the Creative Commons Attributions 2.5 India license. The shape file was created using the administrative atlas of Census 2011, India. And the map was projected in WGS 1984 UTM zone $43 \mathrm{~N}$.

\section{Declaration of competing interest}

The authors declare no conflict of interest.

\section{Acknowledgment}

The authors have no support or funding to report

\section{Appendix A. Supplementary data}

Supplementary data to this article can be found online at https:// doi.org/10.1016/j.cegh.2020.01.006.

\section{References}

1. World Health Organization. Care of the Preterm and Low-Birth-Weight Newborn: World Prematurity Day-17 November 2018. Geneva: World Health Organization; 20182018.

2. Crosse EA, Alder RJ, Østbye T, Campbell MK. Small area variation in low birth weight: looking beyond socioeconomic predictors. Can J Public Health. 1997;88(1):57-61.

3. Kieffer EC, Alexander GR, Lewis ND, Mor J. Geographic patterns of low birth weight in Hawaii. Soc Sci Med. 1993;36(4):557-564.

4. Shiono PH, Behrman RE. Low birth weight: analysis and recommendations. Future Child. 1995:4-18.

5. Adams MM, Alexander GR, Kirby RS, Wingate MS. Perinatal Epidemiology for Public Health Practice. Springer Science \& Business Media; 2010.

6. Collier SA, Hogue CJ. Modifiable risk factors for low birth weight and their effect on cerebral palsy and mental retardation. Matern Child Health J. 2007:11(1):65-71.

7. Goldenberg RL, Culhane JF. Low birth weight in the United States-. Am J Clin Nutr. 2007;85(2):584S-590S.

8. Fang J, Madhavan S, Alderman MH. Low birth weight: race and maternal 
nativity-impact of community income. Pediatrics. 1999;103(1) e5-e5

9. Pearl M, Braveman P, Abrams B. The relationship of neighborhood socioeconomic characteristics to birthweight among 5 ethnic groups in California. Am J Public Health. 2001;91(11):1808-1814.

10. Villar J, Belizán J. The relative contribution of prematurity and fetal growth retardation to low birth weight in developing and developed societies. Am J Obstet Gynecol. 1982;143(7):793-798.

11. Deshmukh JS, Motghare DD, Zodpey SP, Wadhva SK. Low birth weight and associated maternal factors in an urban area. Indian Pediatr. 1998;35(1):33-36.

12. Kramer MS. Determinants of low birth weight: methodological assessment and metaanalysis. Bull World Health Organ. 1987;65(5):663.

14. Elliot P, Wakefield JC, Best NG, Briggs DJ. Spatial Epidemiology: Methods and Applications. Oxford University Press; 2000.

15. Moore DA, Carpenter TE. Spatial analytical methods and geographic information systems: use in health research and epidemiology. Epidemiol Rev. 1999;21(2):143-161.

16. Tu W, Tedders S, Tian J. An exploratory spatial data analysis of low birth weight prevalence in Georgia. Appl Geogr. 2012;32(2):195-207.

17. Kirby RS, Liu J, Lawson AB, Choi J, Cai B, Hossain M. Spatio-temporal patterning of small area low birth weight incidence and its correlates: a latent spatial structure approach. Spatial Spatio-Temporal Epidemiol. 2011;2(4):265-271.

18. Francis MR, Rakesh PS, Mohan VR, Balraj V, George K. Int J Biol Med Res 2012;3(1):1255-1259.

19. Bangal VB, Gavhane SP, Gagare SD, Aher KH, Bhavsar DK, Verma PR. Changing pattern of birth weight over a decade in rural India. Int $J$ Reprod Contracept Obstet Gynecol. 2017;6(10):4625-4630.

20. Rao S, Yajnik CS, Kanade A, et al. Intake of micronutrient-rich foods in rural Indian mothers is associated with the size of their babies at birth: Pune Maternal Nutrition Study. J Nutr. 2001;131(4):1217-1224.

21. Mesgari MS, Masoomi Z. GIS applications in public health as a decision making support system and it's limitation in Iran. World Appl Sci J. 2008;3(1):73-77.

22. Anselin L. Spatial Econometrics: Methods and Models. vol. 4. Springer Science \& Business Media; 2013.

23. O'campo P, Xue X, Wang MC, Caughy M. Neighborhood risk factors for low birthweight in Baltimore: a multilevel analysis. Am J Public Health. 1997;87(7):1113-1118
24. Subramanian SV, Smith GD. Patterns, distribution, and determinants of under-and overnutrition: a population-based study of women in India-. Am J Clin Nutr. 2006;84(3):633-640.

25. Dharmalingam A, Navaneetham K, Krishnakumar CS. Nutritional status of mothers and low birth weight in India. Matern Child Health J. 2010;14(2):290-298.

26. Ramakrishnan U. Nutrition and low birth weight: from research to practice. Am J Clin Nutr. 2004;79(1):17-21.

27. Akoijam BS, Thangjam ND, Singh KT, Devi SR, Devi RK. Birth weight pattern in the only referral teaching hospital in Manipur. Indian J Public Health. 2006;50(4):220-224.

28. Anselin L. Local indicators of spatial association-LISA. Geogr Anal. 1995;27(2):93-115.

29. Dunlop AL, Salihu HM, Freymann GR, Smith CK, Brann AW. Very low birth weigh births in Georgia, 1994-2005: trends and racial disparities. Matern Child Health J. 2011;15(7):890-898.

30. English PB, Kharrazi M, Davies S, Scalf R, Waller L, Neutra R. Changes in the spatia pattern of low birth weight in a southern California county: the role of individual and neighborhood level factors. Soc Sci Med. 2003;56(10):2073-2088.

31. Anselin L. Exploring Spatial Data with GeoDa TM: A Workbook. 2005. Urbana, IL, USA University of Illinois; 2008:226.

32. Ceesay SM, Prentice AM, Cole TJ, et al. Effects on birth weight and perinatal mortality of maternal dietary supplements in rural Gambia: 5 year randomised controlled trial. BMJ. 1997;315(7111):786-790.

36. Kramer MS, Kakuma R. Energy and protein intake in pregnancy. Cochrane Database Syst Rev. 2003;4(4).

37. Lawn JE, Blencowe H, Oza S, et al. Every Newborn: progress, priorities, and potential beyond survival. The Lancet. 2014:384(9938):189-205.

38. Committee to Study the Prevention of Low Birth weight. Committee to Study the Prevention of Low Birth Weight. Washington DC: Institute of Medicine; 19851985

39. Barker DJP. Mothers, babies, and health in later life. Elsevier Health Sciences; 1998.

40. Sridharan S, Koschinsky J, Walker JJ. Does context matter for the relationship between deprivation and all-cause mortality? The West vs. the rest of Scotland. International journal of health geographics. 2011;10(1):33.

41. Moran PA. Notes on continuous stochastic phenomena. Biometrika. 1950;37(1/ 2):17-23. 